2006-2068: A UNIQUE CAPSTONE PROJECT: BUILDING AN AIRPLANE

Venkitaswamy Raju, State University of New York-Farmingdale 


\section{A Unique Capstone Project: Building an Aircraft}

\section{Introduction}

Capstone courses in engineering and technology provide the means for the graduating students to demonstrate their comprehensive skills and knowledge and their ability to apply those to real world problems. They serve as an important tool in the accreditation process by enabling programs to provide evidence in producing graduates with the following characteristics: 1) strong background in the concepts, tools and techniques associated with the profession, 2) ability to design experiments, gather data and perform engineering analysis, 3) ability to be innovative and apply principles of engineering design, 4) ability to identify and solve problems, 5) ability to work as a member of a team, and be responsible from moral, ethical and social points of view, and 6) ability to work towards continuous improvement in one's own professional practice. In the past, programs such as mechanical, manufacturing, and electrical engineering technologies primarily focused on completion of capstone courses through individual design projects or through small group projects carried out in the labs. Most recently, engineering technology programs have started encouraging and supporting students to undertake complex industry sponsored capstone projects. In many cases, companies have provided logistical support, access to facilities, equipment, and personnel resources and funding for projects that address problems in product design or production processes. In this paper, we present a case study where senior students in mechanical, manufacturing, electrical, computer and aviation technology programs came together to undertake a complex capstone project. The project involved remodeling and retrofitting a general aviation aircraft. It was a major undertaking in terms of resources, complexities in carrying out the project, logistics involved and meeting legal and other requirements. The project was unique in that it offered the means to solve real world problems, and enabled the students to manage the project as it would have been done in industry. Teams of students, technical personnel, industry advisors and mentoring faculty worked together to provide the students with extensive capstone experience in building the aircraft. For the faculty and the students, the project was an excellent means to demonstrate the strengths of the program while meeting the accreditation criteria. The paper describes the project in its entirety and the lessons learned in carrying out a full-scale industry project.

\section{Capstone Senior Projects: Recent Developments}

In recent years, the capstone senior projects have become a very significant element of the undergraduate programs in engineering and technology. A wide variety of approaches to carry out senior projects are followed. They include industry sponsored project in product design, concurrent engineering, and systems analysis and integration; multi-university projects dealing with problems in design, testing, manufacturing and product implementation; and interdisciplinary projects involving students from various disciplines of engineering and technology. The changes in the accreditation criteria for 
engineering and technology programs have helped shape the nature and scope of the senior projects.

There is ample evidence to illustrate the evolution in implementing capstone senior projects in engineering and technology in recent times. McDonald etal., have discussed the changes the Lake Superior State University made in their engineering and technology curricula to meet their senior project requirements [1]. They have indicated that in order to prepare graduates for professional assignments in industry, their senior projects had to focus on developing student confidence, and to strengthen their experience through an year-long project. They used a multidisciplinary team of faculty to help the students carry out the projects. Their experience seems to have included extensive participation by industry and excellent placement for their graduates.

Kumar etal. have described their experiences in conducting multi-university design projects in which teams of students across different campuses have collaborated on design and manufacturing projects [2]. They have described how such projects sensitize students to issues in concurrent engineering and train them in interpersonal skills, communications, and system integration. They were convinced that their approach allowed them to simulate real-world conditions by imposing realistic boundary conditions on the student teams.

Roth and Light have discussed in detail the merits of industry sponsored senior projects at Penn State University [3]. They have outlined numerous benefits arising from their approach to partnering with industry. Specifically, they have identified the following as the befits to the university: 1) Faculty often meet colleagues within the industry who are valuable resources within their areas of specialty; 2) Unique facilities within the industry are visited and may perhaps provide future benefits valuable to the faculty; 3) Research projects, grants, publications, and scholarly activities, and other future collaborations can be a natural extension; 4) Faculty can stay abreast of state-of-the-art practices of industry; for example, costs, software, literature, and design codes; and 5) Faculty occasionally seek part-time faculty to teach specialty courses, and locate them through the industrial representatives.

The lessons learned by faculty and students in carrying out industry sponsored group projects here and elsewhere helped plan for the capstone project at the State University of New York (SUNY). Developing a structured approach to the project, forming project teams, providing technical support to the teams, developing and maintaining extensive documents, scheduling tasks, assuring project continuity, self evaluation by the students as well as group evaluation of the project elements, and complying with the project timelines were considered to be the most critical aspects of managing the project.

\section{The Capstone Project at SUNY: Building an Aircraft}

During 2004-2005 academic year, the faculty in the School of Engineering Technologies at SUNY decided to sponsor a major interdisciplinary project involving building an aircraft for the students enrolled in the senior capstone course. The decision came about 
as a result of their success in carrying out large industry sponsored projects in the previous years. In the recent past, students in electrical, mechanical, manufacturing and computer technology programs have worked together in carrying out highly successful, industry sponsored projects dealing with electronics manufacturing, automation or robotics. The decision to undertake the aircraft building project also emerged as a result of funding and other provisions that have been made possible recently.

The School of Engineering Technologies at SUNY has offered programs in aerospace and aviation technology for over thirty years. The school maintains an airport facility and operates a fleet of more than 20 general aviation aircrafts. The school also maintains a full-fledged aircraft maintenance facility with a technical staff of about ten certified aircraft maintenance technicians. The school's infrastructure also includes facilities and provisions to restore and retrofit a general aviation aircraft. However with such provisions, in the past the school did not sponsor student projects involving aircraft building primarily due to the nature of individual projects carried out by senior students, logistics involved in building an aircraft, and the resources required to undertake such projects.

For the first senior project in aircraft building, it was decided to take an existing, damaged aircraft and retrofit it to airworthiness. Since the aircraft had the basic mechanical structure, well defined design parameters, and the Federal Aviation Administration (FAA) guidelines to meet airworthiness certification, the project provided the students with an excellent starting point. A team of 16 students from mechanical, manufacturing, electrical, computer and aerospace programs formed the project team for the first phase of the project. A team of four aviation maintenance technicians and the maintenance supervisor formed the technical support team. Two senior faculty members from mechanical and aerospace assumed the responsibilities in guiding the project. It was decided to carryout the project in three phases over a two year period.

\section{Building an Aircraft: Project Details}

The main objective of the project was to restore an old Cessna aircraft to airworthy conditions while creating an optimum environment to apply engineering knowledge, and to utilize skills and competencies in product design, team work, and approach to problem solving. The aircraft selected for the project was in service for about ten years before it was decommissioned in 1998. Due to lack of maintenance, parts of the aircraft were corroded and damaged. In 1999, the aircraft was disassembled and the components were stored in a climate controlled room to preserve and prevent further corrosion. An examination of the current conditions of the aircraft revealed that the project would involve rebuilding the entire tail cone section with new skin, replacing several structural components, adding a new floor panel inside the cabin area, replacing the electrical wiring and the control panel, adding new firewall and supporting components, and placing a protective coating to the entire aircraft. 
The project started with a workshop on aerospace and aircraft basics to prepare the nonaerospace students to undertake the project. Over a two week period, the students learned the basics of the Cessna aircraft, its mechanical structure, electrical and communication systems, working mechanisms of the aircraft, airworthiness requirements as per FAA guidelines, and the current conditions of the aircraft. Then the students grouped themselves into two teams to carry out the project. They also divided the project into three components to better manage the logistics in restoration. The tasks to be carried out in each of these component areas are as follows:

\section{Building Aircraft Fuselage}

The tasks involved in this segment are to reattach the landing gear and repair the fuselage to factory specification. This involves performing necessary sheet metal repairs and replacement, undertaking corrosion control measures, and carrying out non destructive testing.

\section{Restoring Wings and Electrical Systems}

The tasks involved in this segment are to replace necessary sheet metal, restore the wings to their specified working conditions, and replacement of the control panel, communication and electrical systems and adding the firewall.

\section{Aircraft Assembly and Testing}

The tasks involved in this segment are to reassemble the aircraft, and attach the wings and other major components. Upon assembly, the aircraft will have to be tested according to FAA guidelines and requirements for airworthiness.

It was determined that it would take two to three senior project classes to complete the project over a three semester duration. It was also determined that elaborate written documents must be kept to provide continuity to the project and to enable the succeeding classes to pick up the project where it was left by the previous groups of students.

In the first phase of the project, the students started working on the assignments in segment one and two. As first step in the process, they took a closer look at the inventory of parts for restoration of the aircraft. They separated and grouped the components according to the parts requirements in each segment of the project. They then prepared a list of parts to be purchased and processed the purchase requirements through the school. They estimated that the project would cost about $\$ 36,000$ without paying for the labor involved in the project. A major component contributing to the total cost of the project was its engine. It was estimated to be about $\$ 22,000$.

Since the students have organized themselves in to teams according to their skills and competencies and to meet the project requirements in each segment, the groups were able to start working on their segment of the project immediately. While the first team worked on the fuselage, the second worked on the electrical systems. A major task for the 
first team was to design and build two jigs to hold the aircraft structure for restoration in the front and the rear of the craft. Equally important task for the second team was laying out the electrical harness and installing the electrical and communication systems. By the time the first group of seniors completed their work for the project in the Fall 2005, they have accomplished their major goals and brought the project to a point, where it would be easy for the next class of seniors to complete the restoration of the aircraft.

\section{Lessons Learned}

The project was a major undertaking for the School of Engineering Technology and to all its participants. For the first time, the seniors worked on a project that led to the development of a very practical and exciting product. The project was truly an interdisciplinary effort involving three departments and five undergraduate programs. It also enabled the students to use their skills and competencies in mechanical, manufacturing, electrical, computer, and aerospace disciplines while presenting an opportunity to learn new concepts and technologies. It brought the faculty and staff to work together to provide the best learning environment for the students while creating new challenges and opportunities. The project also taught some very important lessons for everyone involved. The key among them are as follows:

1. Major interdisciplinary capstone projects are possible only if the university is willing to commit adequate resources. A large budgetary allocation is mandatory for successful completion of such projects as aircraft building.

2. Projects of the kind described here will require extensive technical help from maintenance and operational staff and provisions for such help can only come from an understanding and involved administration.

3. Extensive preplanning and experience in project management are prerequisites to successfully conclude a complex senior project. Close coordination among faculty and staff in the departments involved in the project are essential to its success.

4. Well integrated senior projects, similar to the one described here, would prove to be the most rewarding experience for the graduating students as well as the faculty. However, it is imperative that the provisions of the curricula provide the students with opportunities to carry out a series of smaller projects on their way to undertake the senior project.

\section{Conclusions}

The capstone senior project attempted at SUNY in 2005 was far different from the ones carried out earlier. It presented excellent opportunities and enormous challenges for everyone involved. It also brought excitement, enthusiasm and a great deal of pride for the students and the faculty. While it is easy to advocate that everyone undertake such

projects, limitations on resources, infrastructure, and time and other commitments on the 
part of people may make it difficult for everyone to follow suit. But, for those who attempt at such ventures, there is no better alternative.

\section{References}

[1] McDonald, David; Devaprasad, James, Duesing, Paul; Mahajan, Ajay; Qatu, Mohamad; and Walworth, Maurice " Re-Engineering the Senior Design Experience with Industry-Sponsored Multidisciplinary Team Projects", fie.engrng.pitt.edu/fie96/papers/398.pdf

[2] Kumar, Vijay; Kinzel, Gary; Wei, Stan; Bengu, Golgen and Zhou, Jack, " Multiuniversity Design Project", Journal of Engineering Education (July 2000).

[3] Roth, David and Light, Robert, "Industrially Sponsored Senior Projects: Answers to Tough Questions", http://et.nmsu.edu/ etti/fall98/education/roth/rothfin.html. 